hypochlorite-induced lung injury. Chest 2002; 121 : 573-81.

3 Wahn H, Hammerschmidt S. Influence of cyclooxygenase and lipoxygenase inhibitors on oxidative stressinduced lung injury. Crit Care Med 2001; 29: 802-7.

4 Menaouar A, Anglade D, Baussand P, et al. Chlorine gas induced acute lung injury in isolated rabbit lung. Eur Respir J 1997; 10: 1100-7.

\section{Cerebral infarction following carotid arterial injection of adrenaline}

To the Editor:

Neurological injury following internal jugular venous cannulation has been reported frequently. ${ }^{1-5} \mathrm{We}$ report a case where the injection of adrenaline into the carotid artery led to cerebral infarction.

A 24-yr-old female diagnosed with septic shock was being sedated, ventilated and required high inotropic/vasopressor support. During a routine check of her right internal jugular venous catheter (her only iv access), it wasn't possible to aspirate blood and so all infusions were stopped. Following left sided 'internal jugular vein' cannulation (fixed at $13 \mathrm{~cm}$ ) the patient had a run of premature ventricular contractions, which led to ventricular fibrillation. As a part of the cardiopulmonary resuscitation, three rounds of adrenaline were injected and a pressurized infusion of Hartmann's solution started through this new ' $i v$ ' access. Following successful resuscitation after about ten minutes, blood was seen to flow-back into the infusion drip. A suspicion of our ' $i v$ ' catheter, actually being intra-arterial, arose. The line was transduced and an arterial waveform confirmed our suspicion. The right femoral vein was then cannulated, the 'intraarterial' catheter removed and the site firmly pressed for a few minutes.

A neurological examination performed six hours later demonstrated exaggerated right-sided deep tendon reflexes with a positive Babinski's sign. A computed tomography scan of the head revealed a diffuse ischemic infarction of the left frontal and parietal regions. Bedside echocardiogram and Doppler studies of the left carotid artery were done to rule out the presence of any thrombus or atheromatous plaque. Despite aggressive management, the patient deteriorated and died after about $24 \mathrm{hr}$ of the episode. There was no evidence of any thrombus/emboli on autopsy.

As the known causes of neurological injury, in this scenario, were not obvious, we suppose it was the adrenaline injected during resuscitation that caused a transient constriction of the carotid artery and/or its branches. This vasoconstriction, maintained by repeated injections of adrenaline, compounded by the compromised circulation (produced by external cardiac compressions), led to ischemic infarction of the brain. If our assumption, based on available evidence, is correct, it raises a few significant questions; how justified is it to attempt a central venous line placement (specially internal jugular) in a patient who is severely hypotensive or 'in cardiac arrest'? Would the use of a 2D ultrasound be useful in such 'resuscitation scenarios'? We would appreciate comments from other readers, if they can suggest any other possible cause and/or solutions for this catastrophe.

Neeraj Saxena MD

Munish Sharma MD

Delhi, India

\section{References}

1 Briscoe CE, Bushman JA, McDonald WI. Extensive neurological damage after cannulation of internal jugular vein. Br Med J 1974; 23: 314.

2 Anagnou J. Cerebrovascular accident during percutaneous cannulation of internal jugular vein (Letter). Lancet 1982; 14: 377-8.

3 Sloan MA, Mueller JD, Adelman LS, Caplan LR. Fatal brainstem stroke following internal jugular vein catheterization. Neurology 1991; 41: 1092-5.

4 Zaidi NA, Khan M, Naqvi HI, Kamal RS. Cerebral infarct following central venous cannulation. Anaesthesia 1998; 53: 186-91.

5 Oblgisser M, Kanfman T, Taitelman U, Bursztein S, Birkban JH. Cardiac arrest following a complication of internal jugular vein cannulation. Anaesthesia 1979; 34: 1035-7.

\section{Erratum}

Dans l'article intitulé: “The posterior lumbar plexus (psoas compartment) block and the three-in-one femoral nerve block provide similar postoperative analgesia after total knee replacement [Le bloc du plexus lombaire par voie postérieure (loge du psoas) et le bloc du nerf fémoral trois-en-un produisent une analgésie similaire après une arthroscopie totale du genou]" publié dans le numéro de Janvier 2004, Can J Anesth 2004; 51: 45-51, le terme "arthroscopie" dans le titre français devrait se lire "arthroplastie". 